\title{
A CONTRIBUTION TO OUR KNOWLEDGE OF THE NATIONAL GAME OF SKILL OF AFRICA.
}

\author{
By P. A. WAGNer. \\ (With Plates XIII-XVII.) \\ (Read April 19, 1916.)
}

Among most of the native races of Africa there is played in one form or another, either in rows of holes scooped out of the ground or on wooden, stone, or even ivory boards, a peculiar game of skill, that from its wide distribution over the continent has been appropriately styled "the national game of Africa."

As a matter of fact it is not confined to Africa, being practised in Syria, Arabia, Bombay, Ceylon, the Malay Peninsula, Java, and indeed along the entire southern coast of Asia as far as the Philippine Islands. $\dagger^{+}$It is also played by the negroes of the Barbadoes, Martinique and San Domingo, and, as will be presently pointed out, was in 1891 "presented to the civilised world for its diversion," by an enterprising American firm, as "a game of skill for two players." $\uparrow$

It is essentially a war-game. Two players or sides direct a contest between armies of equal strength, the object in view being the capture or "killing" of " men," who are represented by small stones, seeds, shells, or fragments of dry cow-dung. + It is often played for a stake, but is certainly not a gambling game as maintained by some writers. Another common belief, strangely at variance with the generally accepted estimate of the intellectual capacity of the African native, is that the game is very intricate. This is quite erroneous, though it undoubtedly calls for a certain facility in ready reckoning.

The game is clearly of very considerable antiquity: It was already

* Cf. Stewart Culin, Rept. Smithsonian Institution, 1893-1894, pp. 597-607.

+ Cf. Culin, loc. cit.

$\ddagger$ According to Culin ivory balls are used by the chiefs of the Vei tribes of: West Africa. 
known to the Arabs in the Middle Ages, being referred to in the commentary to the Kitab al Aghani, the "Book of Songs"; * and stone boards $\dagger$ and fragments of boards - some of them obviously very old-identical with those in use at the present day, are found in, and in the neighbourhood of, the ancient ruins of Southern Rhodesia.

At the present day many varieties of the game are in existence, but while these differ considerably among themselves they all present sufficient identity of feature to justify the assumption that they have a common ancestry. In regard to its origin diverse views prevail. Culin, from the comparatively early mention of the game in Arabic literature and the retention of its Arabic name (mancala or manqala) in Northern Africa, concludes that Arabia was the source whence it was disseminated, and regards its distribution as marking the limits of Arab culture. Schweinfurth, + on the other hand, believes that it originated in Central Africa and looks upon its wide diffusion in the continent "as evidence, in its degree indirect and collateral, of the essential unity of the African nations." Until more is known of the distribution and rules of the game in different parts of Africa, it would be idle to dogmatise in regard to these mutually destructive hypotheses, but the facts in our possession appear to the writer to favour the views of Schweinfurth.

The distribution of the game in South Africa is peculiar. It is played by the Hottentots, the Berg Damaras, and by practically all the Bantu tribes with the exception of the Basutoland Basutos, $\S$ the Zulus, Matabele, and the tribes inhabiting the eastern districts of the Cape Province, $\|$ among whom it is, however, being introduced by natives returning from the mine compounds, where it is one of the favourite recreations. There is no evidence to show that the game was ever practised by the Bushman. 9

The writer has only recently taken up the study of the game and is presenting these notes with the object of stimulating interest in and raising discussion on a branch of ethnography that has hitherto been neglected by students of the native races of Africa.

As far as he has been able to ascertain from his own investigations and

* Cf. Culin, loc. cit.

+ Similar game-boards have been found and are depicted in paintings in Egyptian tombs as old as the pre-dynastic period (4000 B.c.), but from the fact that astragels or oblong dice usually accompany the boards, it is presumed that the games played on them were dice-games. Vide Murray, H. J. R., The History of Chess, p. 30.

¥ $f$. The Heart of Africa, vol. ii, p. 29.

$\S$ Among the Basutos of Basutoland the European game of Mill (German"Mühle) is very popular under the name Marabaraba. It was evidently taught them by missionaries.

\| For much of this information the writer is indebted to Mr. H. M. Taberer.

T The game known as Bushman Cards, which is described by G. W. Stow in The Native Races of South Africa, is something totally different. 
from the literature on the subject, which is very meagre, the different varieties of the game may be classified as follows:

(1) Those in which all the pieces or "men" originally on the board* remain in play throughout the game. The Hottentot game of \|Huis exemplifies this variety.

(2) Those in which the captured or killed "men" are removed from the board or placed in a receptacle attached to the board.

The games belonging to the second category can again be subdivided into those-

(a) Played on boards with four parallel rows of holes. Four-row games have a wide distribution in Southern and Eastern Africa as far north at least as the Uganda Protectorate. ${ }^{\dagger}$

(b) Played on boards with two parallel rows of holes. Games of this type are played throughout Western and Northern Africa.

(c) Played on boards with three parallel rows of holes. They are exemplified by the Abyssinian game of Gabattà.

It is proposed in the following pages to give a description of games belonging to each of these groups.

\section{I.-The Game of $\|$ Hìs or Otjitoto.}

The game of $\| H \bar{u} s$ (holes) is played under that name by the Namaqua Hottentots and Berg Damaras of South-West Africa, and under the name Otjitoto (also meaning holes) by the Hereros or Cattle Damaras. The Berg Damaras and Hereros are said to have learned the game from the Hottentots. The writer has heard it stated that the same game is played by the Ovambos inhabiting the extreme northern portion of South-West Africa, but has not succeeded in obtaining any definite information on this point.

The rules of $\| H \bar{u} s$ are briefly described by Leonhard Schultze in his admirable work Aus Namaland und Kalahari, but so far as the writer is aware no detailed account of the game has hitherto been published. It is played in four parallel rows of holes made in the ground or scooped out of sand, there being an even number of holes in each row. When only two players participate it is not customary to have more than twelve holes in a row, but when there are two or more players on each side, as is frequently the case, there may be twenty-four or more holes in a row. The players squat or kneel on opposite sides of the board facing one another.

* In the present paper the word "board" is used not in its literal sense, but to denote a surface of play, whether it be an actual board or merely a series of parallel rows of holes scooped out of the ground.

$+C f$. Sir H. H. Johnston, The Uganda Protectorate, p. 795. 
At the beginning of a game each player* places two pieces-small stones, seeds, or fragments of dried dung-in each of the holes of his outer row, and the same number in each of the holes in the right half of his inner row as shown in Fig. 1, I.

The object of the game is to capture all the pieces of one's adversary or to put him in a position in which he is no longer able to move any of his pieces. The moves are made alternately. The mode of progression consists. in each of the players in turn taking up the contents of any of the holes on his side of the board, in which there are two or more pieces, and distributing: these one at a time in a counter-clockwise direction in the succeeding holes of the same row. If the last of the pieces thus taken up and distributed by one of the players is dropped into an empty hole, his move comes to an end and his opponent plays. If, on the other hand, it is dropped into an occupied hole, one of two things happens :

(a) If the hole in question is in his inner row and has opposite it in the inner row of his opponent an occupied hole he is entitled to capture (\|am) the pieces in this hole, together with those in the corresponding hole of his opponent's outer row ; the "men" thus captured being distributed one at a time in the succeeding holes of his inner row. $\dagger$ Thus in Fig. 1, III 1, for example, the player $\mathrm{Q}$ has just finished a move by dropping a "last man" in hole $c-7$. As this hole was occupied-it now contains three piecesand the hole $b-7$ in P's inner row is also occupied, he is entitled to capture the single piece in $b-7$ and the two pieces in $a-7$. He does so, the appropriation being represented by a black rectangle, and drops the captured pieces one at a time into $c-6, c-5$ and $c-4$ (Fig. 1, III 2) where his move comes to an end.

(b) If the hole in his opponent's inner row, opposite to the one in which his last piece was dropped, is not occupied; or if the last of the pieces he took up is dropped into one of the holes in his outer row containing one or more pieces, he has to continue his move by taking up all the pieces in the hole in question, including the one that he dropped, and distributing them as before. A number of instances of this occur in the game described on the following pages.

Under no circumstances may a move be inaugurated from a hole containing a single piece. When, therefore, a player has only one piece in each of his occupied holes, he can no longer move and loses the game. $\| H \bar{u} s$ differs in this respect from all the games to be subsequently dealt with.

A player will sometimes play for safety by transferring the bulk of his pieces to the holes of his outer row. The Hottentot describes this manœuvre

* The description refers to a two-handed game.

+ Or of his outer row if the hole or holes in which the "men" were captured are at the end of the board. 
by the word !Koenie, meaning he runs away. If, on the other hand, a player assumes a vigorous offensive and succeeds in capturing all the pieces in two or more consecutive holes belonging to his adversary, he is said to hit him on the head $(\ddagger$ Nou).

There is a good deal in the game when played by experienced players, who will sometimes sit for hours over a single contest; victory usually falling to the player whose ability to foresee positions, and to calculate rapidly in what hole any particular move will end is the more developed. When played in a village or werft it invariably attracts spectators, who follow the moves with the greatest interest and vie with one another in offering suggestions to the players; a practice that frequently leads to quarrels.

To render the rules of the game quite clear the complete record of a contest between two players $\mathrm{P}$ and $\mathrm{Q}$ is appended. In the diagrams, the holes are represented by open squares, the pieces by black dots and the appropriation or capture of pieces by a black rectangle or square.

II a.-The Games of Maruba, Mofuba, Tschuba and Chuba.

Maruba.

Maruba is the favourite recreation of the Bapedi inhabiting the northern, western and southern portions respectively of the Middleburg, Lydenburg and Zoutpansberg districts of the Transvaal. It is played on a board consisting of four parallel rows of holes, the number of holes in each row being dependent upon the number of players. A row generally contains an even number of holes, but there is no definite rule on this point.

At the beginning of a game each player puts two pieces (mathlapa) in each of the holes (mekoti) of his outer row and the same number in each of the holes of his inner row, except the one on the extreme left, which is left empty, and the one next to it, into which only a single piece is placed (Fig. 5, I and Plate XVI). The first player may start his move from any of the holes in his inner row containing two pieces or from any hole in his outer row. The pieces are moved in a counter-clockwise direction in exactly the same manner as in $\| H \bar{u} s$; a move continuing until the last of the pieces taken up from any particular hole is dropped into an empty hole. If the hole in question is in the player's outer row his move comes to an end, and this also happens if it is in his inner row and the corresponding hole in his opponent's inner row is empty. If, on the other hand, the hole is in his inner row and has opposite it, in the inner row of his opponent, an occupied hole, he is entitled to "kill" (tlaba) the pieces in this hole and the corresponding hole in his opponent's outer row, and is moreover entitled to capture (tlola) 
Transactions of the Royal Society of South Africa.

Fig. 1.

I. - Shows the position of the pieces at the commencement of the game. The privilege of playing first is, as is usual in these games, left to agreement or chance, being considered of no great importance. In subsequent games, however, the winner of the first contest takes the lead.

II-II a.-We will assume that P starts. Two courses are open to him. He may take the two pieces out of hole $b-6$ and drop them in $b-7$ and $b-8$ (Fig. 1, II), or pick up the two pieces in $a-6$ and distribute them in $b-7$ and $b-8$ (Fig. 1, II $a$ ). Only at the beginning of a game is it permitted to move pieces from the outer to the inner row in this manner. In the game under description P makes move II.

III.-Q takes the two pieces in $c-9$ and drops them in $c-8$ and $c-7$. He thereby, as already explained, captures the three pieces in $b-7$ and $a-7$ and distributes these in $c-6, c-5$ and $c-4$.

IV. - P picks up the two pieces in $b-3$ and drops them in $b-4$ and $b-5$. As $b-5$ was already occupied he by this move captures the three pieces in $c-5$ and $d-5$ (Fig. 1, IV 1), and distributes them in $b-6, b-7$ and $b-8$. He takes the five pieces in $c-8$ and $d-8$ (Fig. 1, IV 2) and distributes them in $b-9, b-10, b-11, b-12$ and $a-12$; picks up the three pieces in $a-12$ and drops them, one at a time, into $a-11, a-10$ and $a-9$ (Fig. 1, IV 3); takes the three pieces in $a-9$ and distributes them in $a-8, a-7$ and $a-6$; takes up the three pieces in $a-6$ and drops them in $a-5, a-4$ and $a-3$; picks up the three pieces in $a-3$ and distributes them in $a-2, a-1$ and $b-1$; picks up the three pieces in $b-1$ and distributes them in $b-2, b-3$ and $b-4$. He captures the three pieces in $c-4$ and $d-4$ (Fig. 1, IV 3) and distributes them in $b-5, b-6$ and $b-7$ (Fig. 1, IV 4) ; captures the five pieces in $c-7$ and $d-7$ (Fig. $1, \mathrm{IV} 4$ ) and drops them in $b-8, b-9, b-10$, $b-11$ and $b-12$; captures the four pieces in $c-12$ and $d-12$ (Fig. 1 , IV 5) and distributes them in $a-12, a-11, a-10$ and $a-9$ (Fig. 1, IV 6). The dropping of a "last man" into the now empty hole $a-9$ brings his move to an end. 
The National Game of Skill of Africa.

FIG. 1.

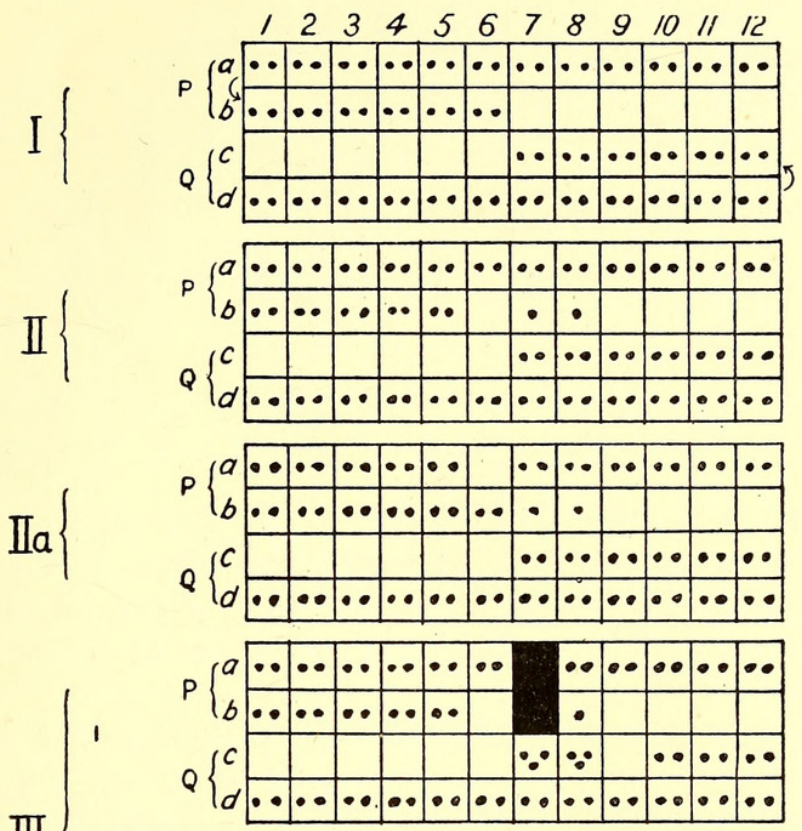

III

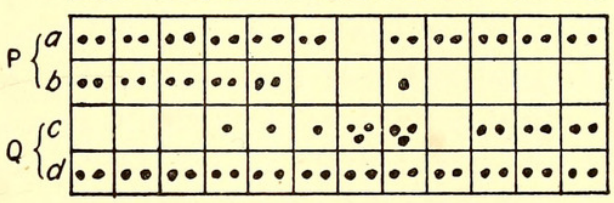

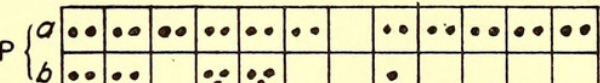

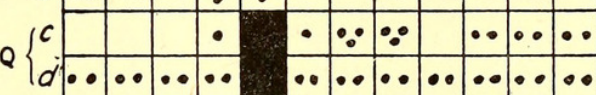

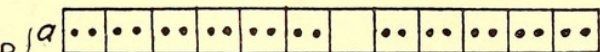

$\left\{\begin{array}{llllllll} & \cdots & \cdots & \because & \because & \bullet & \bullet & \cdots\end{array}\right.$

2

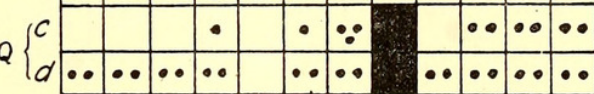

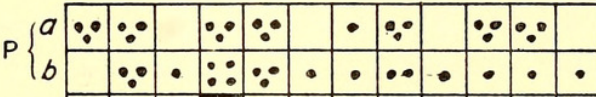

3

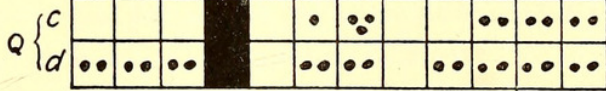

IV

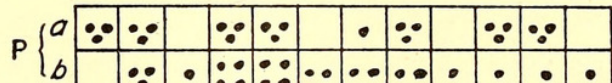

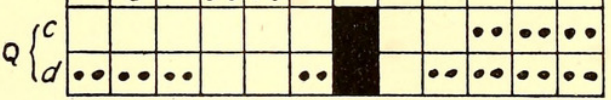

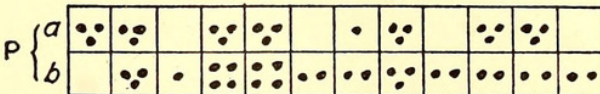
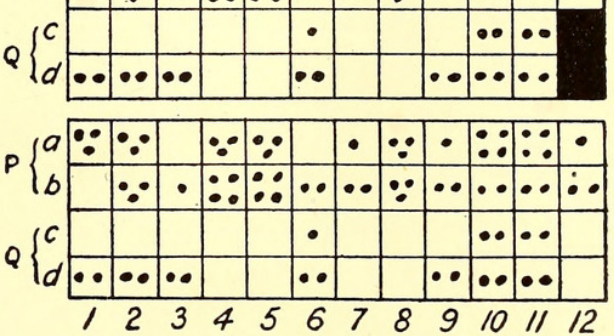
FIG. 2.

V. - Q picks up the two pieces in $d-9$ and drops them into $d-10$ and $d-11$; takes the three pieces in $d-11$ and drops them into $d-12, c-12$ and $c-11$. He captures the six pieces in $b-11$ and $a-11$ (Fig. 2, V) and distributes them in $c-10, c-9, c-8, c-7, c-6$ and $c-5$, where his move comes to an end (Fig. 2, V 2).

VI.-P takes two pieces out of $b-6$ and drops them in $b-7$ and $b-8$. He captures the single piece in $c-8$ (Fig. 2, VI 1) and drops it into $b-9$; captures the single piece in $c-9$ (Fig. 2, VI 2) and drops it into $b-10$; captures the six pieces in $c-10$ and $d-10$ and drops them into $b-11, b-12$, $a-12, a-11, a-10$ and $a-9$; picks up the two pieces in $a-9$ and drops them in $a-8$ and $a-7$; picks up the two pieces in $a-7$ and drops them in $a-6$ and $a-5$; picks up the four pieces in $a-5$ and distributes them in $a-4, a-3, a-2$ and $a-1$; takes the four pieces in $a-1$ and distributes them in $b-1, b-2, b-3$ and $b-4$ (Fig. 2 , VI 5 ); picks up the five pieces in $b-4$ and distributes them in $b-5, b-6, b-7, b-8$ and $b-9$; picks up the four pieces in $b-9$ and distributes them in $b-10, b-11, b-12$ and $a-12$; takes the three pieces in $a-12$ and distributes them in $a-11, a-10$ and $a-9$, where his move ends.

VII.-Q picks up the two pieces in $d-1$ and drops them in $d-2$ and $d-3$; takes the three pieces in $d-3$; takes the three pieces in $d-3$ and distributes them in $d-4, d-5$ and $d-6$; takes the three pieces in $d-6$ and distributes them in $d-7, d-8$ and $d-9$.

VIII.-P takes the two pieces in $b-3$ and drops them into $b-4$ and $b-5$. IIe captures the two pieces in $c-5$ and $d-5$ (Fig. 2, VIII 1) which are distributed in $b-6$ and $b-7$; he captures the two pieces in $c-7$ and $d-7$ (Fig. 2, VIII 2) and distributes them in $b-8$ and $b-9$, (Fig. 2, VIII 3), where his move ends. 
The National Game of Skill of Africa.

FIG. 2.

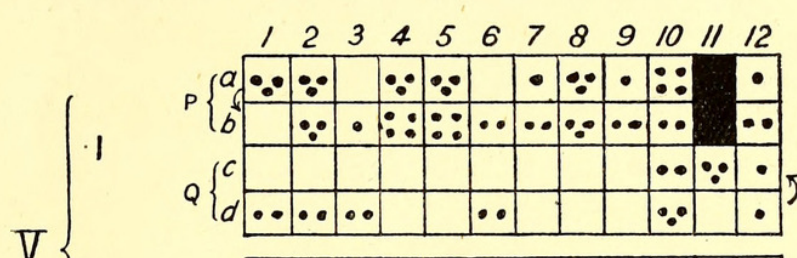

V 2

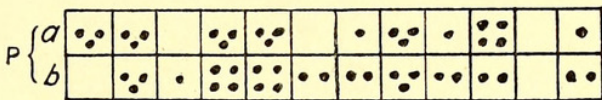

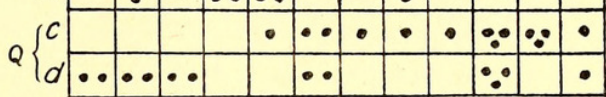

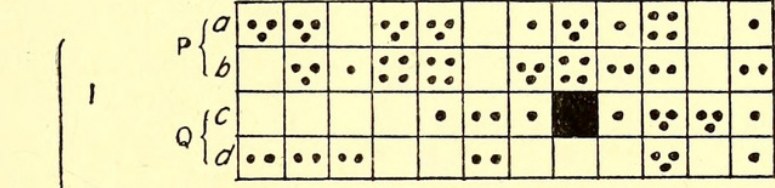

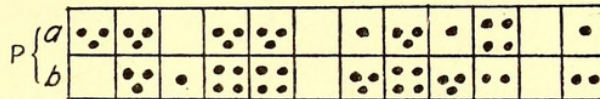

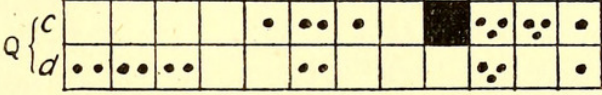

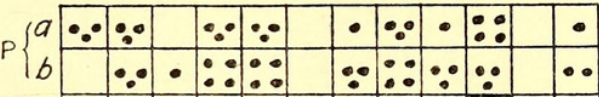

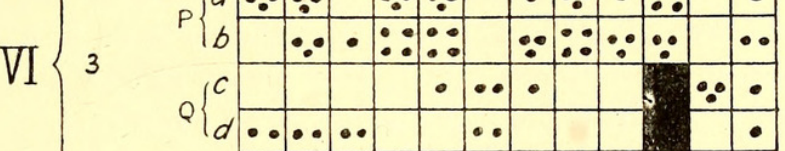

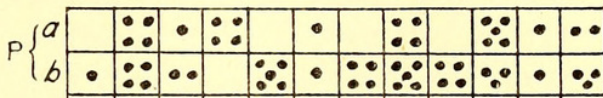

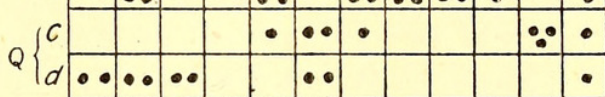

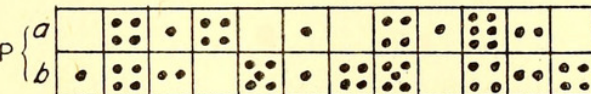

5
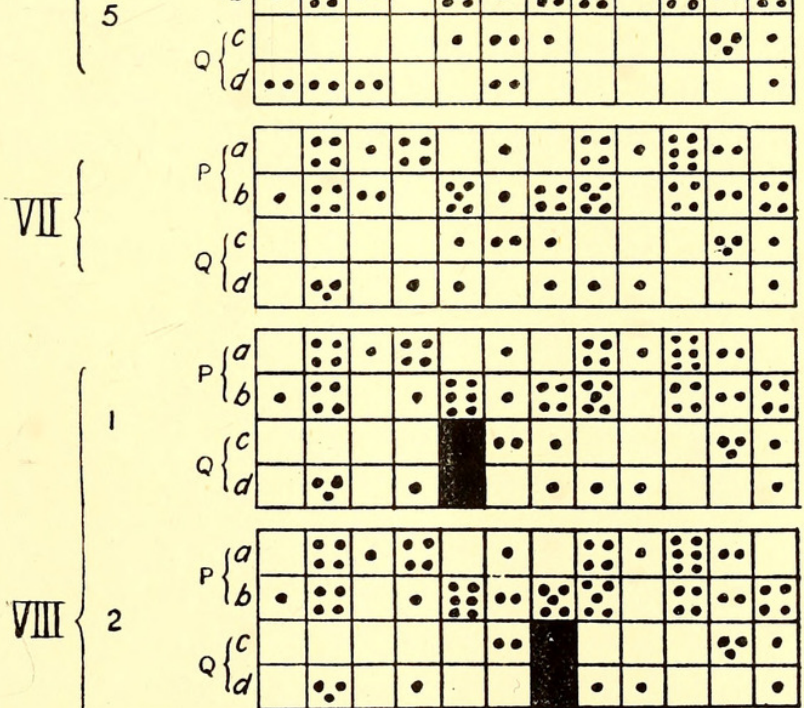

3

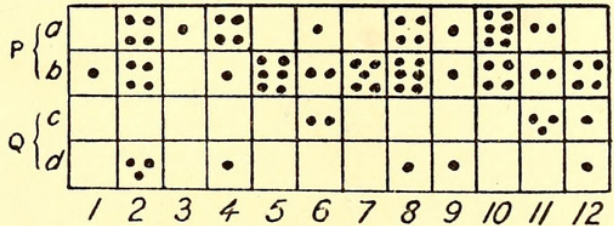


Fig. 3.

IX.-Q picks up the three pieces in $d-2$ and distributes them in $d-3, d-4$ and $d-5$, where his move stops.

$\mathrm{X}$. $-\mathrm{P}$ takes the four pieces in $b-2$ and drops them into $b-3, b-4, b-5$ and $b-6$. $\mathrm{He}$ captures the two pieces in $c-6$ (Fig. 3, X 1) and distributes them in $b-7$ and $b-8$. He picks up the seven pieces in $b-8$ and distributes them in $b-9, b-10, b-11, b-12, a-12, a-11$ and $a-10$ (Fig. 3, X 2); picks up the seven pieces in $a-10$ and distributes them in $a-9, a-8, a-7, a-6$, $a-5, a-4$ and $a-3$; picks up the two pieces in $a-3$ and drops them in $a-2$ and $a-1$, where his move comes to an end.

XI. $-\mathrm{Q}$ picks up the two pieces in $d-4$ and drops them in $d-5$ and $d-6$.

XII.-P picks up the two pieces in $b-9$ and drops them into $b-10$ and $b-11$. He captures the three pieces in $c-11$ (Fig. 3, XII 1) and drops them into $b-12, a-12$ and $a-11$; picks up the four pieces in $a-11$ and distributes them in $a-10, a-9, a-8$ and $a-7$; picks up the two pieces in $a-7$ and drops them in $a-6$ and $a-5$; picks up the two pieces in $a-5$ and drops them into $a-4$ and $a-3$.

XIII.-Q picks up the two pieces in $d-5$ and drops them into $d-6$ and $d-7$.

XIV. $-\mathrm{P}$ takes seven pieces out of $b-5$ and drops them in $b-6, b-7, b-8, b-9$, $b-10, b-11$ and $b-12$. He captures the two pieces in $c-12$ and $d-12$ (Fig. 3. XIV 1) and drops them in $a-12$ and $a-11$, where his move ends. 
Fig. 3.
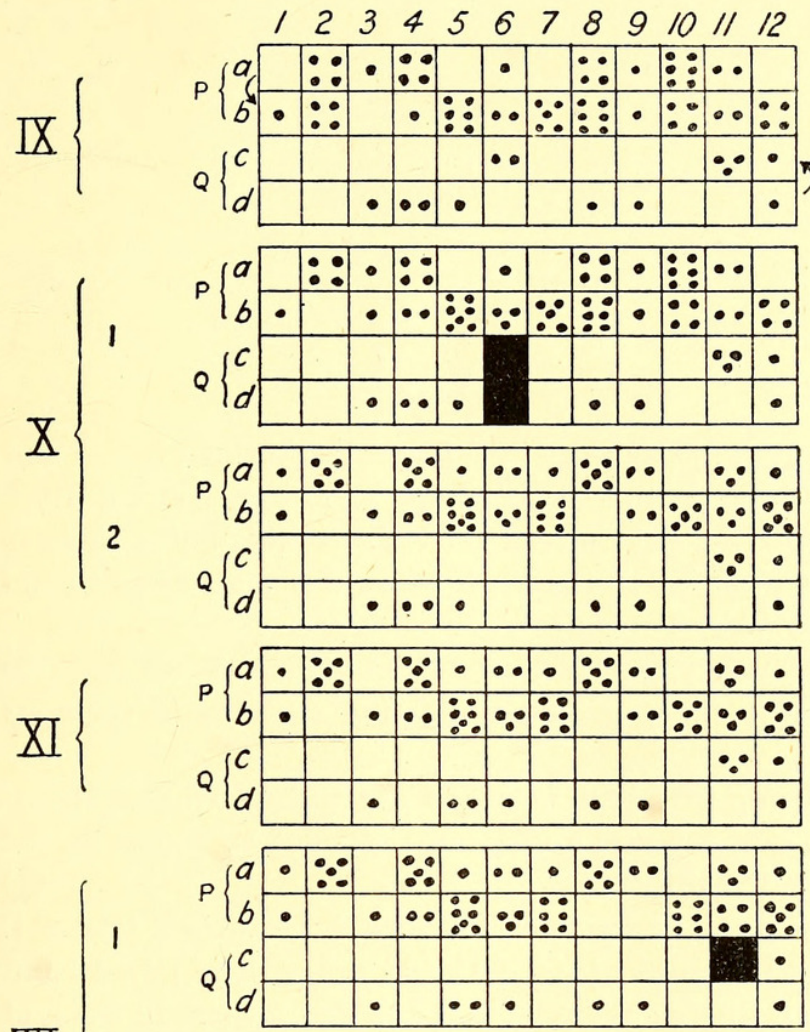

XII

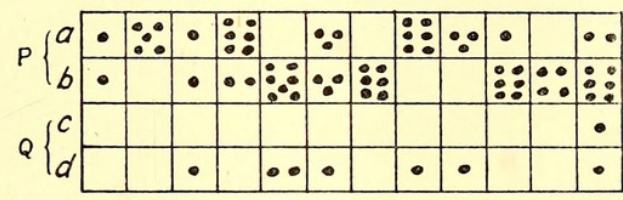

XIII
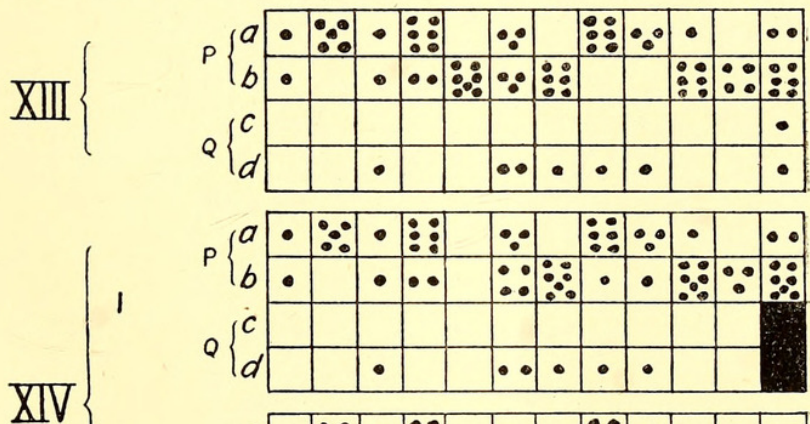

XIV

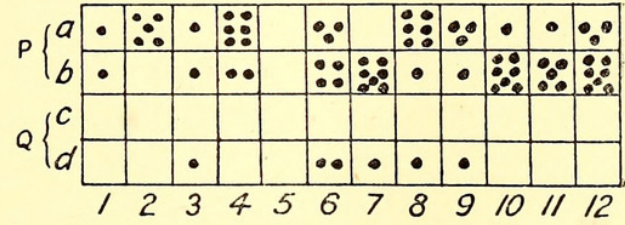


Fig. 4.

XV.-Q picks up the two pieces in $d-6$ and drops them in $d-7$ and $d-8$; picks up the two pieces in $d-8$ and drops them in $d-9$ and $d-10$.

XVI.-P picks up the three pieces in $a-12$ and distributes them in $a-11, a-10$ and $a-9$; picks up the four pieces in $a-9$ and drops them in $a-8, a-7$, $a-6$ and $a-5$.

XVII.-Q takes two pieces out of $d-7$ and drops them into $d-8$ and $d-9$; picks up the three pieces in $d-9$ and distributes them in $d-10, d-11$ and $d-12$.

XVIII.-P picks up the seven pieces in $a-8$ and distributes them in $a-7, a-6$, $a-5, a-4, a-3, a-2$ and $a-1$; picks up the two pieces in $a-1$ and drops them in $b-1$ and $b-2$.

XIX.-Q picks up the two pieces in $d-10$ and drops them into $d-11$ and $d-12$; picks up the two pieces in $d-12$ and drops them in $c-12$ and $c-11$.

$\mathrm{XX}$. $-\mathrm{P}$ takes up the two pieces in $b-4$ and drops them in $b-5$ and $b-6$; picks up the five pieces in $b-6$ and drops them in $b-7, b-8, b-9, b-10$ and $b-11$. He captures the three pieces in $c-11$ and $d-11$ (Fig. 4 , XX 1) and drops them in $b-12, a-12$ and $a-11$; picks up the three pieces in $a-11$ and drops them in $a-10, a-9$ and $a-8$, where his move ends (Fig. $4, \mathrm{XX} 2$ ).

$\mathrm{Q}$ having only one stone in each of his occupied holes is unable to move, and $\mathrm{P}$ thus wins the game. 
Fig. 4.
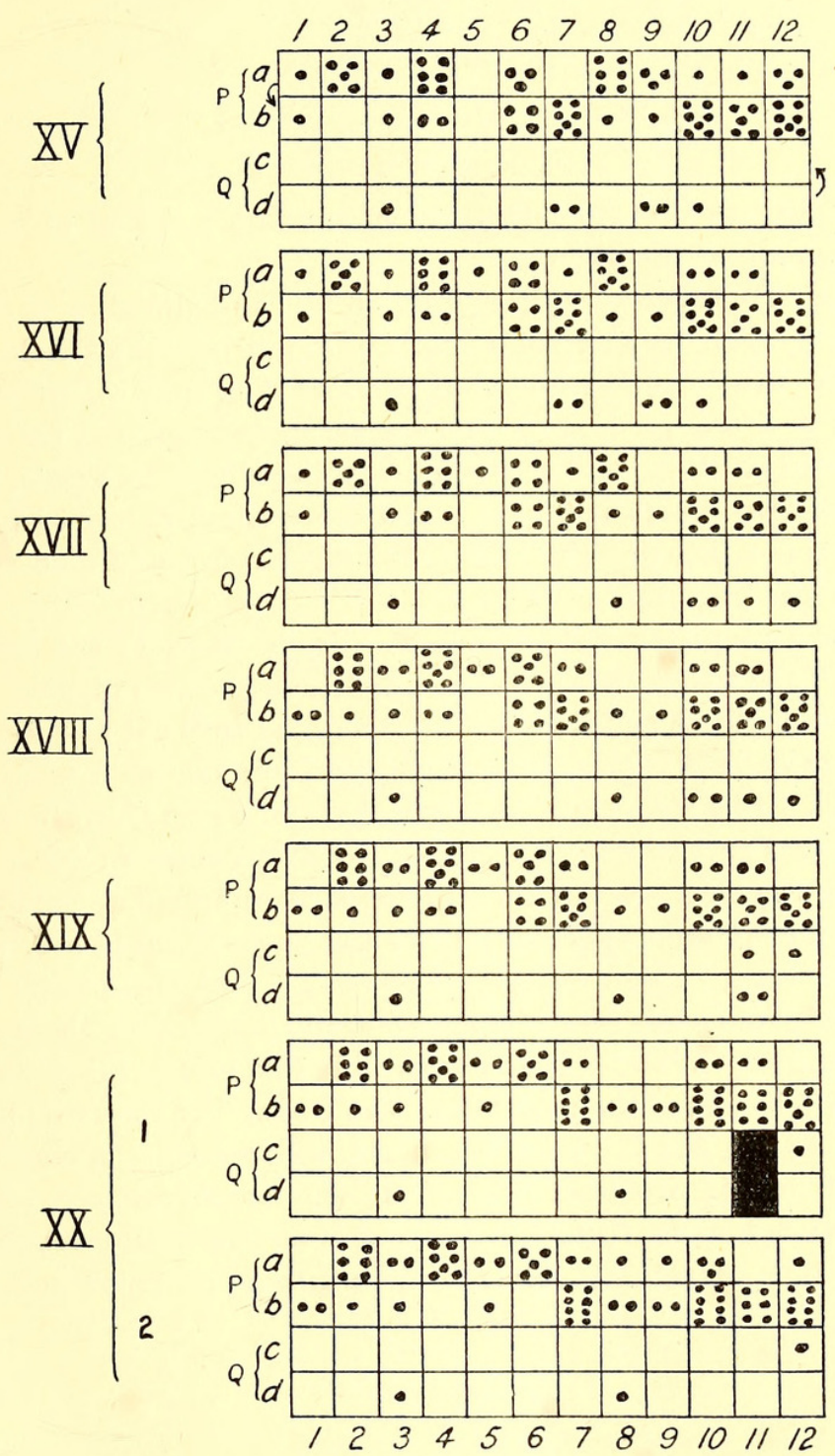
Fig. 5.

I.-This diagram, as already intimated, shows the position of the pieces at the opening of the game.

II.-P starts. He takes two pieces out of $b-6$ and distributes them in $b-7$ and $b-8$. The dropping of a single stone in the empty hole $b-8$ entitles him to "kill" the four pieces in $c-8$ and $d-8$, and to capture the two pieces in $d-6$ (Fig. 5, II 1). All six pieces are removed from the board, the position at the end of the move being shown in Fig. 5, II 2.

III.-Q takes two pieces out of $c-3$ and drops them in $c-2$ and $c-1$. He is thereby entitled to "kill" the four pieces in $b-1$ and also captures the two pieces in $a-2$.

IV. $-\mathrm{P}$ takes two pieces out of $b-4$ and drops them in $b-5$ and $b-6$. He "kills" the two pieces in $c-6$ and captures the two in $c-5$.

V. $-Q$ takes two pieces out of $c-2$ and drops them into $c-1$ and $d-1$; takes up the three pieces in $d-1$ and distributes them one at a time in $d-2, d-3$ and $d-4$; takes the three pieces in $d-4$ and drops them in $d-5, d-6$ and $d-7$; takes three pieces out of $d-7$ and drops them in $d-8, c-8$ and $c-7$; takes three pieces out of $c-7$ and drops them in $c-6, c-5$ and $c-4$ (Fig. 5, V 1); takes three pieces out of $c-4$ and drops them in $c-3, c-2$ and $c-1$ (Fig. 5, V 2); takes three pieces out of $c-1$ and drops them in $d-1, d-2$ and $d-3$; takes the four pieces in $d-3$ and distributes them in $d-4, d-5$, $d-6$ and $d-7$. As $d-7$ was an empty hole this brings his move to an end.

VI.-After a few moves the position of the "men" of the two players is as shown in Fig. 5, IX. It is Q's move, who has only a single piece left in each of his occupied holes. He may start from $c-8, c-6, c-3, d-1$, $d-3$ or $d-7$, but not from $c-4, d-5$ or $d-6$, as this would mean his playing from a hole containing only one piece into an occupied hole. 
The National Game of Skill of Africa.

Fig. 5.

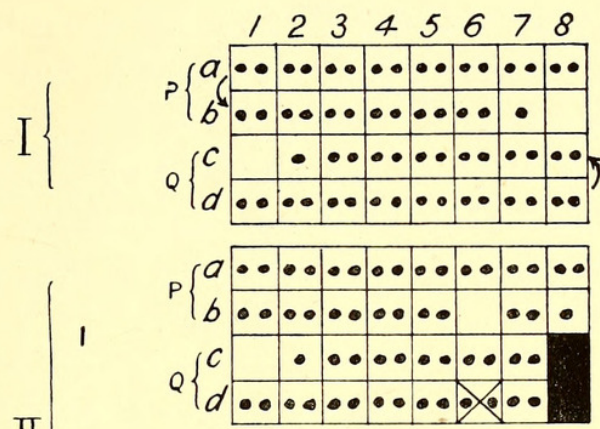

III
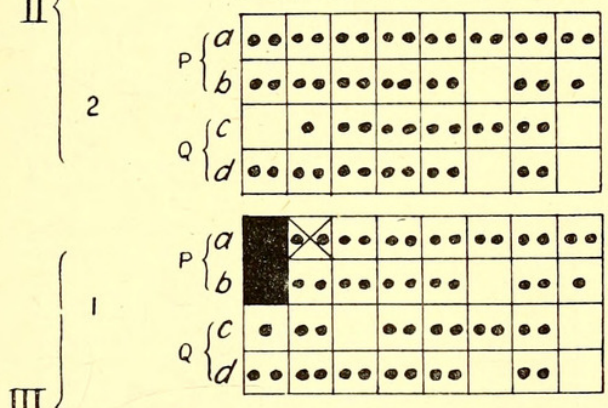

III

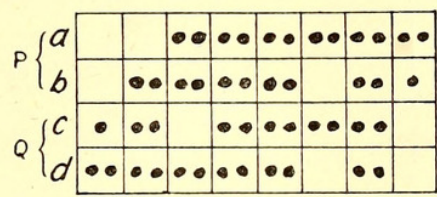

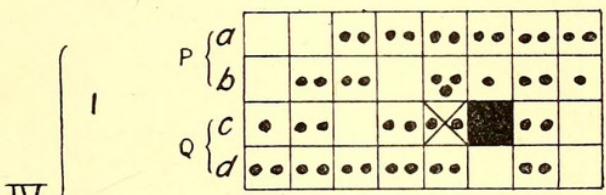

IV

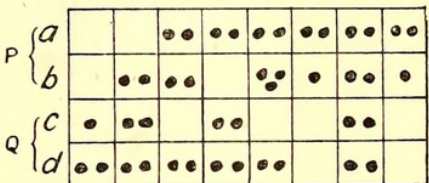

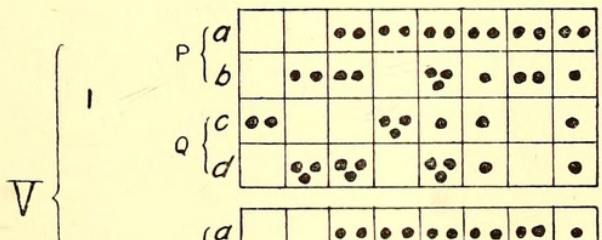

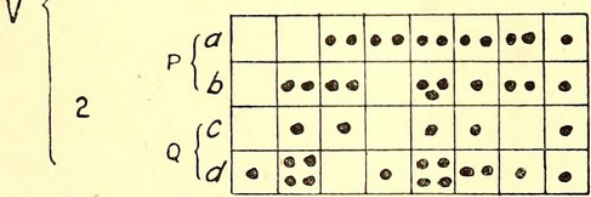

IX

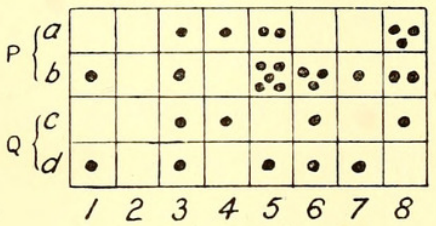


the pieces contained in any other hole belonging to his opponent; the "killed" and captured pieces being all removed from the board.

As long as a player has more than one piece in any of his holes ghe may not begin a move from a hole containing a single piece. When, however, he has only one piece left in each of his occupied holes he is at liberty to start from any of these holes that does not necessitate his playing? into an occupied hole. Play continues until the board is cleared,"and the party who has "killed" and captured most pieces wins.

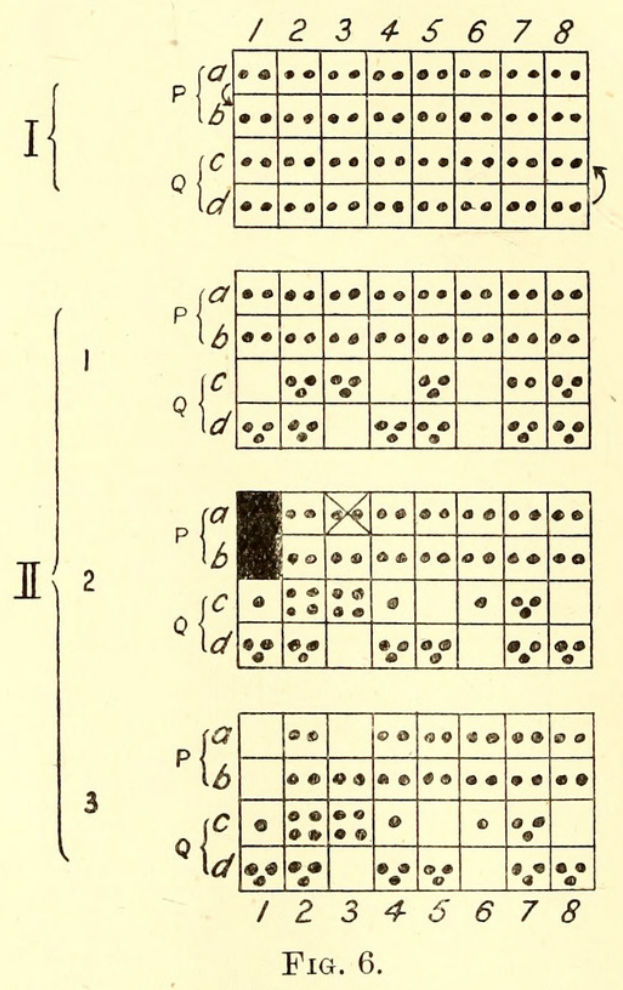

The rules briefly outlined in the preceding paragraphs will be rendered clear by the following record of a number of moves in a game in which the writer actually participated. The "killing" is represented by a black rectangle or square and the supplementary capture of pieces by a cross.

Mofuba.

Identical in every detail with Maruba is the game of Mofuba practised by the Bawenda, who inhabit the northern portions of Zoutpansberg and Waterberg districts of the Transvaal.

The Mashona also play a four-row game called 'M'fuba, but whether or not this is identical with the Mofuba of the Bawenda the writer has not been able to ascertain. 


\section{Tschuba.}

The game of Tschuba* played by the Thonga or Shangaans, who occupy a vast extent of country along the east coast of South Africa between St. Lucia Bay (lat. S. $28^{\circ}$ ) and the Rhodesian Sabi River, is also practically the same as Maruba. Indeed, it only differs from Maruba in the manner in which the pieces are arranged at the commencement of a game, two pieces being placed in each of the holes of both the outer and inner rows (Fig. 6, I). This involves a great deal of preliminary moving of pieces on the part of the first player. Thus assuming that $Q$ starts (Fig. 6, II 1). He takes two pieces out of $c-6$ and distributes them in $c-5$ and $c-4$; takes the three pieces in $c-4$ and drops them in $c-3, c-2$ and $c-1$; takes three pieces out of $c-1$ and drops them into $d-1, d-2$, and $d-3$; takes three pieces out of

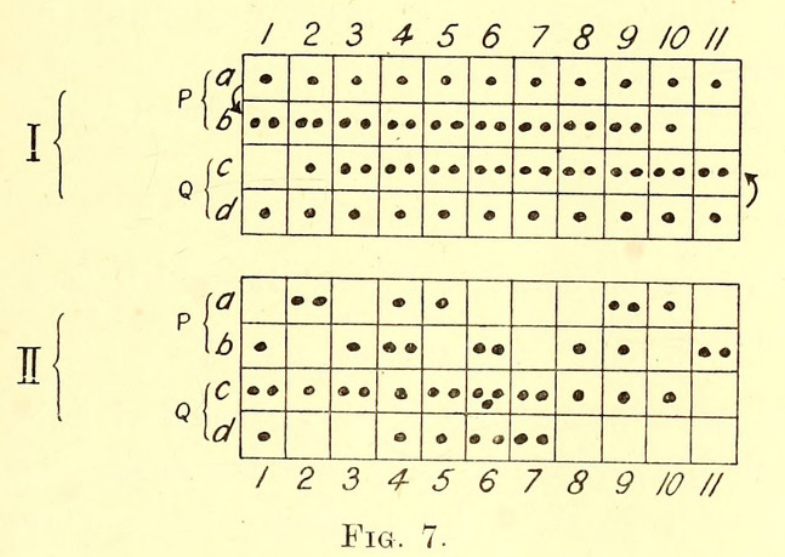

$d-3$ and drops them into $d-4, d-5$ and $d-5$; takes three pieces out of $d-6$ and drops them into $d-7, d-8$ and $c-8$ (Fig. 6 , II 1 ); takes three pieces out of $c-8$ and drops them in $c-7, c-6$ and $c-5$; takes four pieces out of $c-5$ and drops them in $c-4, c-3, c-2$ and $c-1$. The dropping of a single stone into the now empty hole $c-1$ entitles him to capture ( $k u$ tha) the four pieces in $b-1$ and $a-1$ and to "kill" (dlaya) the pieces contained in any other hole. He selects $a-2$ and removes all six pieces from the board, the position at the end of his move being shown in Fig. 6, II 3. It will be noted that, as compared with Bapedi and Bawenda usage, the terms "capture" and "kill" are interchanged.

There is also another form of Tschuba, which differs from the one just described in that a player on capturing the contents of one or two holes, as the case may be, is entitled to "kill" all the pieces in any pair of his adversaries' holes. For example, in the game above dealt with, Q on

* An admirable description of the game of Tschuba is given by Henri A. Junod in The Life of a South African Tribe, vol. i, pp. 314-318. 
capturing the pieces in $b-1$ and $a-1$ would be entitled to "kill" the pieces in $a-2$ and $b-2$ or in any other pair of holes.

\section{Chuba.}

The game of Chuba, , published in the United States in 1891 by the Milton Bradley Company, of Springfield, Mass., who described it "as an adaptation from a rude game of eastern Africa," is without doubt derived from the games of Maruba and Tscliuba. It is played on a board with four parallel rows of holes or pockets, eleven in each row, and sixty small beads used as men or counters. Apart from the fact that only one man is placed in each of the holes of the outer rows, the arrangement of the pieces at the commencement of a game is exactly the same as in Maruba (Fig. 7, I). The rules of the game, on the other hand, are identical with those of the second form of Tschuba. Thus in Fig. 7, II, assuming that $\mathrm{Q}$ has just finished a move by dropping a last "man" in $c-4$, he can take all the pieces in $b-4$ and $a-4$ and is also entitled to remove those in any other pair of pockets, such as $b-9$ and $a-9$.

\section{IIb.-The Games of Annana, Djamo, Poo, Kale and Mankal'ah.}

\section{Annana.}

Games played on a board with only two rows of holes are exemplified by Annana, which appears to be very popular among the natives of the Gold Coast. $\uparrow$ There are six holes in each of the rows, and four pieces are placed in each hole at the commencement of a game. As in all the previously described games, the players in turn move their pieces in a counter-clockwise direction by distributing them one at a time in the holes ahead; a move continuing right round the board until the last of the pieces taken up from any particular hole on his side by one of the players is dropped into an empty hole or into a hole containing three pieces, thus making four. In the former event his move stops and his opponent plays; in the latter event he is entitled to remove the four pieces from the board. If, during a move, four pieces should collect in any hole other than that at which the move ends, these go to the plaver if the hole or holes are on his side of the board and to his adversary if the hole or holes are on the opposite side of the board. Play continues until the board is cleared, and the player who has captured most pieces wins the game. A move may at any time be inaugurated from a hole containing a single piece.

The following is the record of the first three moves of a game of Annana:

* Cf. Culin, loc. cit.

$\uparrow$ The writer learnt the game from an educated native hailing from Accra. 


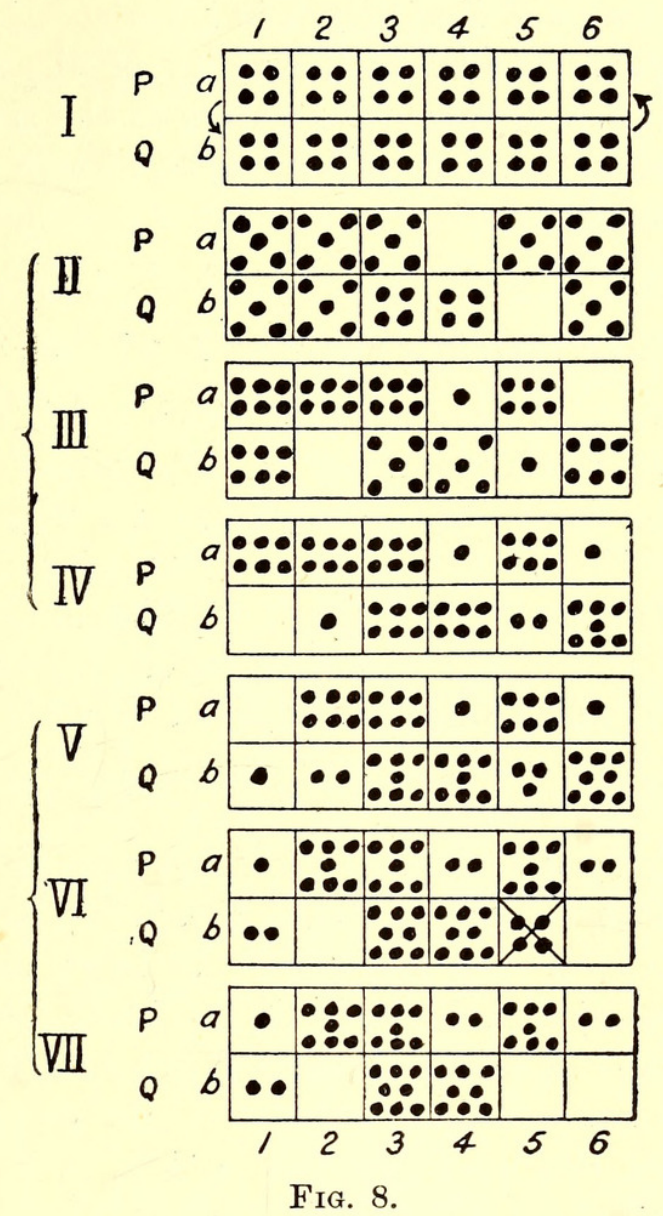

I.-Shows the"position of the pieces at the opening of the game.

II-IV.-Q starts. He takes the four pieces in $b-5$ and distributes them in $b-6, a-6, a-5$ and $a-4$; takes the five pieces in $a-4$ and drops them one at a time into $a-3, a-2, a-1, b-1$ and $b-2$; takes five pieces out of $b-2$ and drops them in $b-3, b-4, b-5, b-6$ and $a-6 ; a-6$ being an empty hole his move comes to an end. The position of the pieces at this stage of the game is shown in Fig. 8, IV.

V-VII.-P takes up the six pieces in $a-1$ and distributes them in $b-1, b-2$, $b-3, b-4, b-5$ and $b-6$; takes the eight pieces in $b-6$ and distributes them in $a-6, a-5, a-4, a-3, a-2, a-1, b-1$ and $b-2$; takes three pieces out of $b-2$ and drops them in $b-3, b-4$ and $b-5$. There being now four pieces in $b-5$ (Fig. 8 , VI) he captures these, and by removing them from the board brings his move to an end (Fig. 8, VII). 
Djamo and Poo.

The games of Djamo and Poo, played in Liberia, and the game of Kale, * practised by the Fans inhabiting the valley of the Gaboon River, are practically identical with Annana; and games of the same type are played as far south at least as Elmina in Angola, as witness the board depicted in Plate XV, Fig. 2.

\section{The Egyptian Game of Mankal'ah.}

The Egyptian game of Mankal'ah, of which a full description is given by Lane, $\uparrow$ is also very much like Annana. It is played, according to Lane, on a board of twelve holes arranged in two rows, with seventy-two small shells (cowries) or pebbles.

There are two modifications of the game that differ from one another in the manner in which the pieces are distributed at the start of a contest.

In the so-called "game of the ignorants" one of the parties distributes all the pieces (hasa) unequally among all the holes (beyts) generally by putting at least four in each hole.

In the so-called "game of the wise, or intelligent," the pieces are distributed in one or more holes on one side and in the corresponding hole or holes on the other side. Commonly in four holes on each side, leaving the two extreme holes at opposite ends of the board vacant $(a-3, a-4, a-5$, $a-6$ and $b-1, b-2, b-3, b-4$ in Fig. $8, \mathrm{I}$; or atout half the pieces are put in the end hole of one row and the remainder in the diagonally opposite end hole on the opposite side ( $a-6$ and $b-1$ in Fig. 8, I). The person who distributes the pieces does rot count how many he places in the holes, and should his adversary object to the distribution he may turn the koard round.

The mode of progression in koth games is the same as in Annana, and a move continues until the last of the pieces taken up by one of the players is dropped into an empty hole or into a hole containing one or three pieces, thereby completing two or four. In the former event the move stops. In the latter event the player takes the two or four pieces together with those in the hole opposite. If one or more of the holes preceding the one in which the move ends also contain two or four pieces, no hole with any other number intervening, he is moreover entitled to take the contents of these holes $\ddagger$ together with the contents of those opposite. Play continues until the board is cleared, when each party counts the number of pieces he has

* Cf. Culin, loc. cit.

$\dagger$ Cf. An Account of the Manners and Custcms of the Modern Egyptians, pp. 315-317.

* Presumably only when the holes in question are on his side of the board. 
taken, and the one who has most reckons the excess of his above his adversary's number as his gains. The winner is entitled to play first in the next contest, the adversary having first distributed the pieces. When either party has made his successive gains amount to sixty he has won the game.

\section{The Syrian Game of Mancala or Manqala.}

In Mancala as played in Syria* the board consists of fourteen holes arranged in two rows, and seven pieces are placed in each row. Otherwise the games-there are again two-are identical with the Egyptian games.

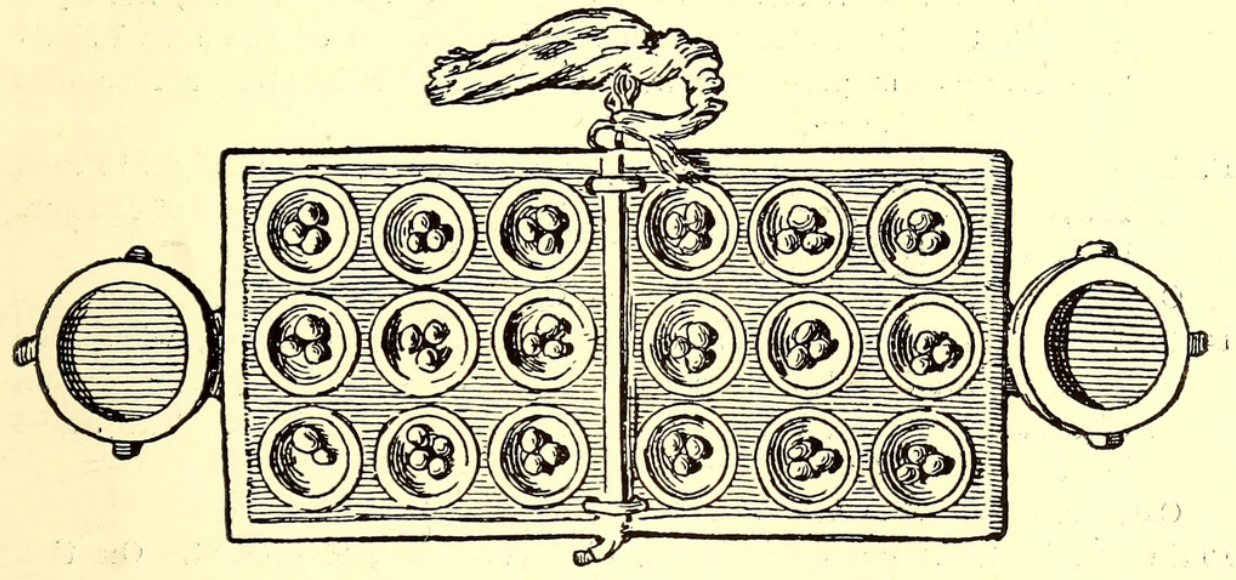

Fig. 9.-Board for Gabattà (after Th. Bent).

\section{IIc.-The Abyssinian Game of Gabattì.}

In this game, briefly referred to by Bent in The Sacred City of the Ethiopians, the board, as previously intimated, consists of three paralle rows of holes. There are six holes in each row, and at the commencement of the game three pieces are placed in each hole.

According to Bent it "is played by a series of passing which seemed to us very intricate and which we could not learn; the holes they call their toukouls or huts, and they get very excited over it. It closely resembles the game we saw played by the negroes in Mashonaland."

The writer's special thanks are due to Dr. L. Peringuèy for the photographs reproduced in Plate II and Plate III, fig. 1, and to the Acting. Curator of the Alexander McGregor Memorial Museum, Kimberley, for the photograph reproduced in Plate I; also to Mr. E. H. Banks for having assisted him in the preparation of Figs. 1-8. 


\section{EXPLANATION OF PLATES XIII-XVII.}

Plate XIII.--Portion of a chlorite-schist game-board, with four rows of holes, found near an "ancient" ruin on the De Beers Ranch, Belingwe District, Southern Rhodesia. (About one-third of the actual size.) The original is preserved in the Alexander McGregor Memorial Museum, Kimberley.

Plate XIV, fig. 1.-Stone game-board with four rows of holes, eight in each row, Que Que, Southern Rhodesia. The board has a length of $435 \mathrm{~mm}$. and a width of $265 \mathrm{~mm}$.

Cat. No. 1608, South African Museum, Cape Town.

Plate XIV, fig. 2.-Portion of a weathered stone game-board, with four parallel rows of holes and a large pocket on one side for the reception of captured pieces, Umtali District, Southern Rhodesia. The board has a length of $575 \mathrm{~mm}$. and a width of $330 \mathrm{~mm}$.

Cat. No. 1364, South African Museum, Cape Town.

Plate XV, fig. 1.-Stone game-board, from Veekraal, Transvaal. On this board four parallel rows, each of eight holes, are superimposed on an older series of holes. The board is $510 \mathrm{~mm}$. in length and $460 \mathrm{~mm}$. in width.

Cat. No. 1584, South African Museum, Cape Town.

Plate XV, fig. 2.-Board for Mbau, Elmina, Angola. After Stewart Culin. The large pockets at the opposite ends of the board are for the reception of captured pieces.

Plate XVI. - The start of a two-handed game of Maruba.

Plate XVII.-The game in progress. 


\section{$2 \mathrm{BHL}$ Biodiversity Heritage Library}

Wagner, P. A. 1917. "A CONTRIBUTION TO OUR KNOWLEDGE OF THE NATIONAL GAME OF SKILL OF AFRICA." Transactions of the Royal Society of South Africa 6, 47-68. https://doi.org/10.1080/00359191709520174.

View This Item Online: https://www.biodiversitylibrary.org/item/181547

DOI: https://doi.org/10.1080/00359191709520174

Permalink: https://www.biodiversitylibrary.org/partpdf/175567.

\section{Holding Institution}

Smithsonian Libraries

\section{Sponsored by}

Biodiversity Heritage Library

\section{Copyright \& Reuse}

Copyright Status: Not in copyright. The BHL knows of no copyright restrictions on this item.

This document was created from content at the Biodiversity Heritage Library, the world's largest open access digital library for biodiversity literature and archives. Visit BHL at https://www.biodiversitylibrary.org. 